\title{
Simulated die-rolling behaviours express illusions of control in regular gamblers
}

\author{
Lim, Matthew S. M.; Rogers, Robert D.
}

\section{International Gambling Studies}

DOI:

$10.1080 / 14459795.2019 .1652668$

Published: 01/01/2020

Peer reviewed version

Cyswllt i'r cyhoeddiad / Link to publication

Dyfyniad o'r fersiwn a gyhoeddwyd / Citation for published version (APA):

Lim, M. S. M., \& Rogers, R. D. (2020). Simulated die-rolling behaviours express illusions of control in regular gamblers. International Gambling Studies, 20(1), 57-79.

https://doi.org/10.1080/14459795.2019.1652668

\footnotetext{
Hawliau Cyffredinol / General rights

Copyright and moral rights for the publications made accessible in the public portal are retained by the authors and/or other copyright owners and it is a condition of accessing publications that users recognise and abide by the legal requirements associated with these rights.

- Users may download and print one copy of any publication from the public portal for the purpose of private study or research.

- You may not further distribute the material or use it for any profit-making activity or commercial gain

- You may freely distribute the URL identifying the publication in the public portal ?
}

Take down policy

If you believe that this document breaches copyright please contact us providing details, and we will remove access to the work immediately and investigate your claim. 


\section{Simulated die-rolling behaviours express action-based illusions of control in regular (non-problem) gamblers: An investigation of the impacts of prize structures, social facilitation and the modulation of 'motor set'}

Matthew S.M. Lim ${ }^{\mathrm{a}}$ \& Robert D. Rogers ${ }^{\mathrm{b}}$

${ }^{a}$ Department of Psychology, National University of Singapore

${ }^{\mathrm{b}}$ School of Psychology, Bangor University

Address for correspondence:

Dr. Matthew Lim

Department of Psychology

National University of Singapore

Block AS4, \#03-13

9 Arts Link

Singapore 117570

Tel: +6566011189

Fax: +65 67731843

Email: psymlsm@nus.edu.sg 


\begin{abstract}
Cognitive errors about gambling games, probability and chance outcomes can contribute to the incidence of gambling-related harm in vulnerable individuals. Illusions of control (IOC) - beliefs that actions or rituals can influence ostensibly probabilistic game outcomes - are typically studied using questionnaires, think-aloud methods, or inferred from shifts in betting patterns following manipulations of IOC. However, naturalistic studies of dice-based games (e.g., 'Craps') suggest that IOC can be manifest in players' motor actions: e.g., rolling the dice hard to hit higher value outcomes. Here, in three experiments, we investigated the action-based expression of IOC while rolling a single computer-simulated die for monetary prizes in samples of community-recruited gamblers. We report (i) that action-based expressions of IOC are dependent on the congruence of game features (i.e., larger winning numbers linked to larger value prizes); (ii) that action-based expressions of IOC can reflect the joint betting of gambling co-actors (as a form of 'illusion of control by proxy') and (iii) that prior induction of motor-caution can weaken the links between the action-based expression of IOC and gamblers' self-report beliefs that game outcomes can be controlled. These data indicate that gambling-related IOC can be expressed in the action repetoires afforded by gambling games; can reflect their structural features and social contexts; and can be disrupted by the modulation of inhibitory control over motor behaviour.
\end{abstract}

Keywords: problem gambling, cognitive behavioural therapy, betting, erroneous cognitions 


\section{Introduction}

Cognitive biases and errors about gambling games can promote the development and maintenance of harmful patterns of gambling (Delfabbro, 2004; Toneatto, Blitz-Miller,

Calderwood, Dragonetti, \& Tsanos, 1997). They also constitute helpful therapeutic targets for cognitive behavioural interventions for gambling problems (Fortune \& Goodie, 2012; Ladouceur et al., 2003; Ladouceur et al., 2001). However, at the current time, surprisingly little is known about how cognitive biases and errors are expressed in the actions afforded by gambling games (Martinez, Bonnefon, \& Hoskens, 2009). Learning more could help us to improve therapeutic interventions and, perhaps, identify more effective harm-minimsation interventions.

One of the most salient of gambling-related cognitive errors are illusions of control (IOC) (Langer, 1975). IOC involve beliefs that particular actions, prayer, the use of lucky numbers, rituals or charms can influence the outcomes of chance-based games (Raylu \& Oei, 2004; Rothbaum, Weisz, \& Snyder, 1982), and are strengthened in individuals with gambling problems compared to healthy controls (Moore \& Ohtsuka, 1999; Myrseth, Brunborg, \& Eidem, 2010; Raylu \& Oei, 2004; Xian et al., 2008). A large number of experiments indicate the dependence of gamblers' IOC on several situational factors. First, active involvement - defined as a "physical interaction with the gambling device, which triggers the (quasi) immediate resolution of the gamble" (Martinez et al., 2009, p. 1063) can enhance IOC. Active involvement relate to actions in games such as the picking of cards from a deck or balls from a container, or rolling of dice (Chau \& Phillips, 1995; Davis, Sundahl, \& Lesbo, 2000; Dunn \& Wilson, 1990; FernandezDuque \& Wifall, 2007; Martinez et al., 2009; Strickland, Lewicki, \& Katz, 1966). 
Second, IOC in gamblers, like other populations (E J Langer, 1975), appear to depend upon the perception that ostensibly chanced-based games actually involve ill-defined forms of skill, exemplified by observations that gamblers provided with a stopping device on electronic gambling machines report strengthened IOC and lengthen gambling sessions (Ladouceur \& Sevigny, 2005). Finally, IOC in gamblers can be sensitive to the motivational properties of game outcomes. Gamblers who expected painful electric shocks on losing roulette plays were more likely to attempt to control game outcomes using a braking device compared with gamblers who were not under the threat of electric shocks (Friedland, Keinan, and Regev, 1992).

Like other gambling-related erroneous cognitions, IOC has traditionally been measured using self-report (Raylu \& Oei, 2004; Steenbergh, Meyers, May, \& Whelan, 2002); or 'think aloud' methods that capture verbal reports of the thoughts that come to mind whilst playing gambling games (Delfabbro \& Winefield, 1999, 2000; Griffiths, 1994; Ladouceur, Gaboury, Bujold, Lachance, \& Tremblay, 1991; Walker, 1992); or inferred from shifts in betting strategies following manipulations that strengthen (or weaken) IOC in chance-based games (Langer 1975; Burger and Cooper 1979; Strickland et al. 1966). These techniques reflect the conceptualisation of IOC as explicit mental or cognitive structures that represent non-veridical beliefs about the potential impacts of personal actions upon the outcomes of gambling games.

In particular contexts, however, IOC can be seen in gamblers'actions within gambling games. Early observational work reported that street-side and casino gamblers sometimes throw dice in different ways in order to achieve or 'hit' specific game outcomes. For example, some 'craps' players report the belief that throwing dice harder tends to produce higher value outcomes while 
throwing gently produces lower value outcomes $($ Henslin, 1967) . These observations link to the practice of 'dice-setting' (e.g., http://www.dicecoach.com/dicesets.asp) that purports to offer ways to increase the probabilities of certain game outcomes by careful orientation and angled throws of the dice. More prosaically, our common experience includes children (and sometimes adults) throwing dice harder or softer while trying to 'hit' (or avoid) certain outcomes (e.g. 'Double-6' or 'Go-to-Jail') in family board games. These observations suggest that IOC could, in some circumstances at least, be expressed and measured through gamblers' actions.

Previously, we used an experimental 'analogue' model to explore action-based IOC in which gamblers were invited to roll a simulated fair 6-sided die for monetary prizes (Lim, BowdenJones, \& Rogers, 2014). As expected, and in line with the above observations, we demonstrated for the first time that a sample of (broadly non-problematic) community-recruited gamblers allowed a single computer-simulated die to roll for longer durations when trying to 'hit' larger winning numbers with larger value prizes compared with trying to hit smaller value winning numbers with smaller value prizes (Lim et al., 2014). These observations demonstrate actionbased expressions of IOC as gamblers vary die-rolls to (somehow) exercise control over game outcomes. These value-dependent behaviours appear analogous to the way that some gamblers' modulate their dice rolls within casinos or street-games (Henslin, 1967; Davis, 2000) and demonstrate that IOC, expressed in motor behaviours, can be captured in the laboratory.

Here, we extend our understanding of action-based expressions of IOC in three experiments. First, the association of longer roll-times of a simulated die with larger winning numbers and prizes suggests that IOC may reflects a stimulus-response compatibility where the actions
Commented [A1]: Matthew, I can't find any reference to So-Jo; is it a commenrcial gambling game? $\mathrm{R}$

Commented [A2]: You definitely need to leave this in $-\mathrm{R}$ 
afforded by a gambling game are coupled to its structural characteristics through shared cognitive representations of magnitude (Andres et al., 2004; Kornblum et al., 1990; Lindemann et al., 2007; Walsh, 2003). Therefore, Experiment 1 investigated directly whether stimulusresponse compatibility underlies the observed action-based expressions of IOC found previously (Lim et al., 2014) by manipulating the congruency of a dice-based game's structural characteristics and then testing their impact on action-based expressions of IOC.

In line with previous IOC investigations (Langer, 1975), Experiment 2 investigates whether action-based expressions of IOC are susceptible to social facilitation effects by which gamblers' perceptions of, and behaviour in, games are modulated by the presence or absence of others (Cole, Barrett, \& Griffiths, 2011; Rockloff \& Dyer, 2007). Social facilitation can alter gamblers' attribution of others' personal skills or control by drawing attention to their successes in gambling games as in so-called IOC 'by proxy'(Wohl \& Enzle, 2009). Social facilitation has been observed in shifts towards risky betting patterns in children and adults (Caron \& Ladouceur, 2003; Cole et al., 2011; Dykstra \& Dollinger, 1990; Hardoon \& Derevensky, 2001; Le Floch, Martinez, \& Gaffie, 2005; Rockloff \& Dyer, 2007) and the effect appears to be dosedependent, increasing incrementally with the number of other individuals participating in games (Rockloff, Greer, \& Fay, 2011). Experiment 2, therefore, introduced a 2-player die-rolling game - the 'Bone Game' - to examine whether the action-based expressions of IOC in games of dice are enhanced by social facilitation and/or encompass IOC by proxy (Wohl \& Enzle, 2009).

Finally, Experiment 3 completes this series by testing whether it is possible to moderate actionbased expression of IOC. If gamblers' IOC can be expressed in the motor actions of dice-based 
games, it should be possible to modulate their expression by manipulating individuals' motor set. Motor-caution training can be achieved by completing a stop-signal task that involves repeatedly cancelling an intended motor action in response to imperative stimuli (Verbruggen, Adams, \& Chambers, 2012). Induction of motor-caution can transiently reduce risky betting patterns in gambling games (Stevens et al., 2015; Verbruggen et al., 2012; Verbruggen et al., 2013). More broadly, motor inhibitory training interventions can alter impulsive health-related and appetitive behaviours (Allom, Mullan, \& Hagger, 2016; Jones et al., 2016). This is important as individuals with gambling problems sometimes show poor inhibitory control (Billieux et al., 2012; Brevers et al., 2012; Goudriaan, Oosterlaan, De Beurs, \& Van Den Brink, 2006). Taken together, these findings raise the possibility that an induced state of motor caution (Jahfari, Stinear, Claffey, Verbruggen, \& Aron, 2010) will disrupt action-based IOC and disrupt self-reported beliefs in the controlabilty of chance-based games. This is explored in Experiment 3.

\section{Experiment 1: Illusions of control and game prize structure}

Observations that regular (broadly non-problem) gamblers will allow a computer-simulated die to roll for longer while trying to hit higher value winning numbers and prize values suggest that IOC can depend upon the correspondences between actions afforded by gambling games and their prize structures as a form of stimulus-response compatibility (Lim et al., 2014). Other data indicate that hand grasping actions are executed faster and with more force when large numbers, rather than small numbers, are presented (Andres et al., 2004; Lindemann et al., 2007)

In Experiment 1, community-recruited regular (but broadly non-problem) gamblers were randomised to three groups. In one 'congruent' group, participants rolled a single computer- 
simulated die where prize values perfectly mapped onto target winning numbers $(10 \mathrm{p}$ for rolling the winning number of ' 1 ' $\ldots$ and $60 \mathrm{p}$ for rolling the winning number of ' 6 '). In another 'incongruent' group, the winning numbers increased from 1 to 6 but the mapped prize values now decreased (60p for the winning number of ' 1 ', $50 \mathrm{p}$ for the wining number ' 2 ' $\ldots$ and $10 \mathrm{p}$ for the winning number of ' 6 '). Finally, in the 'neutral' group, prizes were $35 \mathrm{p}$ regardless of winning number (i.e. 35p for numbers between '1' and '6'). Reflecting Lim et al. (2014), we tested the prediction that action-based expression of IOC will be strengthened in participants of the congruent group but weakened in the participants of the 'incongruent' group for whom the correspondence between the game features and actions is substantially degraded.

\section{Method}

Experiment 1 (and Experiments 2 and 3) were approved by the Central University Research Ethics Committee of ????? University. All participants gave written informed consent.

\section{Participants}

Sixty male adults were recruited from the local community in Oxford, UK, using advertisements placed on a community website for male gamblers. We recruited male gamblers only since males report a higher number of gambling-related cognitive biases compared to female gamblers

(Raylu \& Oei, 2004; Wardle et al., 2010). Participants were asked how frequently they took part in a variety of online and offline gambling activities (but excluding lottery and scratch cards) that are common in this population. Gambling participation was computed by the total frequency of participation across all gambling activities in the past year. Thirty-eight participants $(63.4 \%)$ reported gambling at least once a week, 18 (30\%) gambled 1-3 times a month, and $4(6.7 \%)$ 
gambled at least a few times a year. Our results provide new information about the role of motor actions in the IOC of male individuals with varying gambling involvement (Table 1).

\section{Clinical and psychometric assessments}

Participants in Experiment 1 (as well as Experiments 2 and 3) were excluded if they screened positive for past-month DSM-IV psychological disorders using SCID-I/P (First, Spitzer, Gibbon, \& Williams, 2002). Non-verbal cognitive ability was assessed using the Raven's Progressive Matrices (Raven, 2000). These standardised scores were included as a control regressor in all of the subsequent analyses since decision-making, visual scanning, motor speed and motor dexterity can depend upon cognitive ability in adults (Barry \& Petry, 2008), and could have influenced the variability of gamblers' active involvement in our die-rolling game.

Structured Clinical Interview for Pathological Gambling (SCI-PG; Grant, Steinberg, Kim, Rounsaville, \& Potenza, 2004). Gambling problems were assessed with the SCI-PG. Three participants were identified as probable pathological gamblers (SCI-PG score $\geq 5$ ), distributed one each across the three participant groups. Their removal did not change the pattern or statistical reliability of our findings and so were retained in our sample.

Gambling Related Cognitions Scale (GRCS; Raylu \& Oei, 2004). Participants completed the GRCS and its illusions of control (GRCS-IOC) subscale scores were used in the analyses. The GRCS-IOC assesses instrumental, superstitious behaviours such as 'I have specific rituals and behaviours that increase my chances of winning'. The GRCS-IOC subscale score demonstrated good internal consistency in this sample (as Cronbach's $\alpha=.85$ ). 
Table 1 about here

Dice-control Scale. Participants completed a bespoke scale adapted from previous work (Ladouceur \& Sevigny, 2005) to measure self-reported IOC beliefs in our die-rolling game. Four items were rated on a 7-point Likert scale, with the anchor points of 'Strongly disagree' and 'Strongly Agree': (i) 'Players can influence the die after having activated the play button'; (ii)

'There is a method for controlling the outcome of the die after the play button has been activated'; (iii) 'A winning outcome is due to skill or a combination of skill and chance'; and (iv) 'There are strategies that could enable players to increase their chances of winning after the play button has been activated'. Total scores showed good internal consistency (Cronbach's $\alpha=.91$ ).

\section{Die-rolling game}

Participants played a computerised die-rolling game with a single 6-sided computer-simulated die for monetary prizes. The game lasted for about 6 mins. Participants were informed that the animated die was 'fair' and that they would keep the monetary value of their winnings as a cash pay-out. On each play, participants were first shown an array of the standard six die faces displayed from left-to-right in middle of a standard computer display (Figure 1a). Next, an auditory message, played through a speaker positioned next to the computer, indicated a randomly-selected target winning number. Participants registered that they understood the target number for that play by clicking on the prize value displayed above the winning number.

Following this, participants clicked down on the mouse again to initiate a simulated roll of the die. While the mouse was depressed down, the die spun and bounced off the walls of a green box 
positioned in the middle of the display. Participants could roll the die for as long or as short a duration as they liked before releasing the mouse click to 'throw' the die. After releasing the mouse, the animated die-roll slowed down and comes to a stop.

If the thrown number matched the target winning number, 'WIN \#p!' (where '\#' indicated the prize value) was displayed in white, accompanied by the sound of a coin falling onto a table, to indicate that the prize has been won. If the thrown number did not match the winner number, 'MISS!' was displayed in red, accompanied by a lower frequency audio jingle indicating a loss. The die-rolling game involved no stakes and participants were informed that the monetary value of their winnings would be added to their participation fee. Participants were told that the die was fair. However, the game was programmed so that 18 out of a total of 72 plays (25\%) rather than 12 out of 72 plays (16.7\%) resulted in winning outcomes. This minor deception helped to ensure a sufficient number of winning outcomes per cell across the six die-face values.

Figure 1 about here

\section{Procedure}

Participants attended the laboratory, completed the SCI-PG and the self-report questionnaires before being randomised to one of three experimental groups of the die-rolling game: (i.e., congruent, incongruent, or neutral). Following completion of the die-rolling game, participants completed the Dice-control Scale and collected their winnings before being discharged. 


\section{Data Analysis}

One-way Analysis of Variance (ANOVAs) and Pearson $\chi^{2}$ tests were used to test whether demographic and gambling characteristics differed across the experimental groups. Nonparametric Kruskal-Wallis tests were used where any variable was not normally distributed.

All significance values were taken at $p<.05$.

Our die-rolling game afforded one dependent measure: the duration of die-roll times (ms). Data analysis was completed in two major steps. First, mixed-effects models were used to regress logtransformed die-roll times against the following game features: (i) the (winning) target values (i.e., 1 to 6); (ii) the values of prizes won or lost on the previous play (to control for changes in roll-times following play outcomes); and (iii) the play number to control for fluctuating engagement across the entire length of the game. Gamblers' intercepts and the coefficients for regressors (i) and (iii) were allowed to vary, as random effects, across participants.

Second, to test the hypothesised action-based expression of IOC within each experimental group, one-sample $t$-tests were conducted on the $\beta$-coefficients linking between die-roll times and target value from the previous regression models. These $\beta$-coefficients were then regressed against two dummy variables created for the (a) congruent and (b) incongruent participant groups (against the 'neutral' group as the referent). Additional regressors included (c) total scores on the Dicecontrol Scale; (d) self-reported IOC (as GRCS-IOC sub-scale scores); (e) participants' age; and (f) non-verbal cognitive ability. An additional model added (g) the two-way interaction between participant group (congruent, incongruent vs neutral) and Dice-control scores. 


\section{Results}

The three groups were well-matched in terms of their demographic characteristics and gambling behaviours (all $p>.05$ ) (Table 1). As expected, overall, participants tended to allow the simulated die to roll for longer when attempting to achieve higher winning values, $b=0.018,95 \% C I$

[<0.001, 0.037], $S E=.009$ (Fig. 1b). Working back from the log-transformed data, this equates to an increase in die-roll times of $\approx 22 \mathrm{~ms}$ for every integer increase in the target winning number. Die-roll times tended to shorten as the game progressed, $b=-0.003,95 \% C I[-0.005,-0.001]$, $S E=0.001$, possibly reflecting lowered engagement. Roll times were not much influenced by winning or losing outcomes on the previous play, $b=-0.002,95 \% C I[-0.014,0.001], S E=0.006$.

One-sample $t$-tests against baseline of 0 revealed that participants in both the neutral group and the congruent group significantly extended the durations of their die-rolls with larger target values, $t(19)=2.89, p<.01$, Cohen's $d=.65$ and $t(19)=2.43, p<.05$, Cohen's $d=.54$, respectively. By contrast, participants in the incongruent group did not roll the die for longer or shorter when trying to hit large target winning values, $t(19)=-1.03, p=.32$, Cohen's $d=.23$.

Participants in the neutral group showed significantly stronger associations between their die roll-times and winning targets than the participants in the incongruent group, $b=-0.035,95 \% C I$ [-0.063, - 0.008$], S E=0.014$ (Figure $1 \mathrm{~b}$ and Model 1 in Table 2). By contrast, the strengths of association between die roll-times and target winning number in the neutral and congruent participant did not significantly differ from each other, $b=0.010,95 \%$ CI $[-0.018,0.037]$, $S E=0.014$. Across all three groups, longer die-rolls when attempting to 'hit' larger winning numbers was strongly associated with participants' beliefs that they had at least some control 
over the outcomes of the simulated die, $b=0.004,95 \% C I[0.002,0.007], S E=0.001$. However, this relationship did not substantially differ across experimental group: congruent vs neutral participants, $b<0.001,95 \% C I[-0.007,0.006], S E=0.003$, and incongruent vs neutral participants, $b=-0.002,95 \%$ CI [-0.007, 0.004], SE=0.003 (Model 2 in Table 2).

Table 2 about here

\section{Discussion}

This experiment replicates the findings of Lim et al. (2014) by demonstrating that communityrecruited gamblers can express IOC by allowing a computer-simulated die to roll for longer while trying to 'hit' larger winning numbers and/or higher value monetary prizes. However, these data extend those earlier findings by demonstrating that it is possible to disrupt these actionbased IOC by manipulating the congruency between structural game features (as the magnitudes of winning numbers and prize values). Finally, the observation that participants' $\beta$-coefficients for the association between die-roll durations and target winning numbers/prizes were linked to beliefs that they could exert at least some influence over outcomes suggests IOC can reflect the degree of active involvement observed in dice-rolling games (Henslin, 1967; Davis, 2000).

Experiment 1 examined the dependence of action-based IOC upon structural characteristics of dice-rolling games. Other data indicate that gambling behaviours are sensitive to social faciliators (Caron \& Ladouceur, 2003; Cole et al., 2011; Dykstra \& Dollinger, 1990; Hardoon \& Derevensky, 2001; Le Floch, Martinez, \& Gaffie, 2005; Rockloff \& Dyer, 2007) and that the gambling successes of others can promote IOC 'by proxy' (Wohl \& Enzle, 2009). Experiment 2 
considers whether the action-based expression of IOC can modulated by the participation of gambling co-actors who can bet on either the same or different outcomes of the die-rolling game.

\section{Experiment 2: Illusions of control and social facilitation effects in the 'Bone Game'}

Community-recruited gamblers played a 2-player dice-rolling game in pairs. Sometimes, gamblers placed a small stake or bet on 'hitting' named winning numbers (as the 'shooter') for small monetary prizes. At other times, they were given the opportunity to place a small bet on either the same winning numbers as their partner (now acting as the 'shooter') or on a different winning number. On each play, the house stipulated a 'Bone' number that forfeited both stakes and signalled that the two players should swap roles. This design allowed us to test, using each gambler as his own control, the prediction that the association between gamblers' die-rolls and target winning numbers (when acting as the shooter) are strengthened when their betting partners bet on the same winning numbers (but weakened when their partners place bets on different numbers). We also tested whether the moderation of gamblers' action-based IOC by partners' betting patterns was linked to their rated beliefs in being able to control outcomes.

\section{Method}

\section{Participants}

Thirty-six male gamblers were recruited in the same way as Experiment 1. Four participants were excluded from the final analysis ( to leave an $n$ of 32) because of idiosyncratic behaviours of betting partners who placed bets on the same outcome as the 'shooter' on less than $10 \%$ of the plays. Sixteen participants (50\%) reported gambling at least once a week; $16(50 \%)$ at least once 
a month (see Table 1 for the demographic/psychometrics features). None of the participants met clinical cut-offs for probable pathological gambling (Grant et al., 2004).

\section{The 'Bone Game'}

One participants of each pair was randomly assigned to start as the shooter; the other participant started as the betting partner. Both participants were in the same room and played the Bone Game on a single shared computer terminal. However, each used their own computer mouse.

As in Experiment 1, participants were shown an array of six faces of a standard die on a shared computer display (Figure 2a). An audio message indicated the shooter's winning number which was acknowledged with a single mouse click on the corresponding die-face. Clicking on the target winning number bet a standard stake of $35 \mathrm{p}$ on that outcome. Next, the betting partner was given the opportunity to bet their $35 \mathrm{p}$ stake on the same winning number as the shooter or to choose, and indicate, a different number. To bet on the same target winning number, the betting partner clicked on the '?' sign beside the shooter's target number. To bet on a different target winning number, the betting partner clicked on the '?' sign beside an alternative number randomly assigned by the computer. After the betting partner had placed his bet, the shooter clicked the mouse again to roll a single simulated die for as long a duration as he or she liked before releasing the mouse button to 'throw' the die and reveal the play outcome. Hitting winning numbers paid out at $2-1$ on the $35 p$ stake. Stakes were returned if the shooter missed both his and the betting partner's winning number; the partner's stake was lost if the shooter hit his own winning number; and the shooter's stake was lost if he hit the partner's winning number. 
The final feature of the game was the random assignment of a 'skull and crossbones' to one number other than the shooter's and betting partner's winning numbers. If the die-roll landed on this number, both participants forfeited their stakes and switched roles, with the shooter now becoming the betting partner, and vice versa. Participants were given 500p of 'house money' to play with and each play cost the shooter $5 \mathrm{p}$. The sequence of plays were programmed so that, by the end of the game, both participants had rolled the simulated die 30 times as the shooter.

Gamblers played a 2-min practice round of the game in pairs to acquaint themselves with the responses before starting on the experimental task which lasted for another 10mins.

\section{Procedure}

Participants completed the SCI-PG (Grant, Steinberg, Kim, Rounsaville, \& Potenza, 2004) and the self-report questionnaires before playing the Bone Game. After this, participants completed the Dice-control Scale and collected their winnings before being discharged.

\section{Data Analysis}

First, mixed models were used to regress participants' (log-transformed) die-roll times against the (i) shooter's target winning numbers (i.e., 1 to 6); (ii) betting partner's target winning numbers (i.e., 1 to 6); (iii) 'bone number' (i.e., 1 to 6); (iv) the betting partner's history of betting with the shooter (as measured by the proportion of partners' bets with the thrower in all preceding plays); and (v) the play number to account for fluctuating engagement across the game. In an additional model, an interaction predictor (vi) was added to investigate the interactive effect of the shooters' target values with betting partners' betting histories. Gamblers' intercepts and regressors (i), (ii) and (vi) were entered into the model as random effects while the remaining regressors were 
entered as fixed effects. Second, as in Experiment 1, one-sample $t$-tests were conducted to explore the significance of the $\beta$-coefficients of regressors (i) and (ii) that were taken from the previous analysis. Third, $\beta$-coefficients for (vi) the interaction effect above were also regressed against predictors for age, non-verbal cognitive ability, GRCS-IOC subscale scores and, most importantly, beliefs in control captured by Dice-control Scale scores.

\section{Results}

Participants (while acting as 'shooters') allowed the simulated die to roll for longer while trying to hit larger target values as opposed to smaller values, $b=0.056,95 \% C I[0.019,0.093]$, $S E=0.019$. This equates to an increase in roll-time of $\approx 25 \mathrm{~ms}$ for every value increase in target winning number. Die-roll times were not much influenced by the value of partners' target numbers, $b=0.010,95 \% C I[-0.014,0.034], S E=0.012$, or the value of the 'bone' number, $b=0.005,95 \% C I[-0.019,0.029], S E=0.012$. However, shooters allowed the die to roll for longer as the proportion of partners' bets on the same target winning numbers increased, $b=0.934,95 \%$ $C I[0.536,1.332], S E=0.203$. The association between die-roll times and shooters' target winning numbers - their action-based IOC - was strengthened with the proportion of shared bets between shooter and betting partner (Figure 2b), $b=0.202,95 \% C I[0.075,0.329], S E=0.065$

Figure 2 about here

Confirming again the statistical reliability of action-based OIC, one-sample $t$-tests showed that the association between die-roll times and shooters' target winning numbers (IOC) was significant, $t(31)=5.05, p<.001$, Cohen's $d=.89$, and more so with bets on the same numbers by 
betting partners, $t(31)=9.22, p<.001$, Cohen's $d=1.63$. However, the moderation of shooters' action-based IOC by their partners' history of betting on the same winning numbers was not markedly related to their self-reported beliefs that they could use the dice to influence game outcomes (Table 3), $b<0.001,95 \% C I[-0.010,0.009], S E=0.005$, or their broader illusions of control as GRCS-IOC scores, $b=0.006,95 \% C I[-0.006,0.018], S E=0.006$.

Table 3 about here

\section{Discussion}

These results replicate the demonstration that action expressions of IOC depend upon the prize structure of the die-rolling game (Lim et al., 2014) and, here, in Experiment 1. Regular gamblers with few gambling problems allow a simulated die to roll for durations that mapped on to their own target winning numbers rather than those chosen by a gambling co-actor or, indeed,

numbers associated with the penalty of swapping between the roles of shooter and betting partner (the 'Bone' number). This indicates that action-based IOC are not simply automatic responses to magnitude features within dice games, but are tied principally to an individuals' own target (and intended) winning numbers. As hypothesised, we found that fluctuations of die-roll times as a function of shooters' target winning numbers were amplified by betting partners consistently betting on the same outcomes, suggesting that action-based IOC can be strengthened by the endorsements offered by congruent betting patterns of gambling co-actors.

Finally, we did not find much evidence that gamblers' action-based IOC were linked to their selfreported beliefs in the controllability of Bone Game outcomes (as captured by Dice-control Scale scores). Most likely, individuals' IOC in any gambling form are tethered to the most plausible 
evidence that gambling outcomes are controllable. Possibly, in a social context, beliefs that actions can moderate the outcomes of dice-based gambling game are primarily driven by the immediate supportive evidence of other gambling partners' congruent betting patterns.

Experiments 1 and 2 demonstrate how the action-based expression of IOC can reflect both the structural features of games and social facilitators. Experiment 3 now completes this series by examining testing directly whether it is possible to disrupt action-based IOC by inducing a state of motor caution through performace of a standard stop-signal task (Verbruggen et al., 2012)

\section{Experiment 3: Illusions of control and motor caution}

Community-recruited gamblers were randomly assigned to two groups. In the 'stop-signal training' group, participants completed a standard version of the stop-signal task before the 'neutral' version of the die-rolling game used in Experiment 1 (that offered a single monetary prize of $35 \mathrm{p}$ for all winning target values); in the 'response-training' control group, participants completed a double-response motor training task (without an inhibitory component) before playing the single-player die-rolling game of Experiment 1 . We tested the prediction that motor caution following a stop-signal task will disrupt associations between longer die-rolls and target winning numbers and, possibly, disturb control beliefs as captured by the Dice-control Scale.

\section{Method}

\section{Participants}

Forty male gamblers were recruited from the local community (Table 1). Twenty-one participants $(52.5 \%)$ gambled once a week or more; 19 (47.5\%) gambled at least once a month. None met criteria for probable pathological gambling (i.e. SCI-PG scores $\geq 5$; Grant et al., 2004). 


\section{Motor caution training (Verbruggen et al., 2012)}

Participants completed a binary-choice task to identify squares- or diamonds- presented as imperative signals, on a standard computer display, by clicking on two separate keys, 'c' and 'm' with the middle fingers of each hand. However, on $25 \%$ of the trials, these shapes were highlighted, indicating that participants should respond differently. In the stop-signal group, participants were instructed to refrain from responding (i.e. in the presence of the 'stop'" signal); while participants in the response-training control group were instructed to respond as usual but with an additional press of the spacebar (i.e., as a 'double response' signal). Over the course of 10 blocks of 72 trials, intervals between the imperative and stop signals were adjusted to ensure that, on average, participants withheld responses successfully on about $50 \%$ of the stop trials.

\section{Procedure}

Participants completed all questionnaires before two groups of 20 were randomised to one of the two experimental groups: the 'stop-signal training' and 'response-training' groups. Following the motor training, participants completed the same version of the computerised die-rolling game as for the 'neutral' group of Experiment 1. Following completion of the die-rolling game, participants completed the Dice-control Scale and were given their winnings in the game.

\section{Data Analysis}

Matching of demographic characteristic and gambling behavuours across the participant groups were explored using independent sample $t$-tests, Pearson $\chi^{2}$ tests, and non-parametric KruskalWallis tests. First, to model participants' action-based expression of IOC, mixed-effects models were first used to regress log-transformed die-roll times against the (i) winning target values (i.e., 
1 to 6); (ii) wins or losses on the immediately previous play (i.e., win=1; loss=-1); and (iii) the play number in the game. Gamblers' intercepts and the coefficients of predictors (i) and (iii) were included to vary randomly across participants. Second, these (action-based IOC) $\beta$-coefficients were put through one-sample $t$-tests to explore the significance of these slopes within each participant group. Finally, these $\beta$-coefficients were also regressed against experimental group ('stop-signal training' against 'response-training') alongside predictors for age, non-verbal cognitive ability, Dice-control Scale scores and the GRCS-IOC subscale scores. A further model tested the interaction between group and Dice-control Scale scores.

\section{Results}

Participants of the stop-signal training and response-training groups were well-matched on demographic, clinical and gambling measures $(p>.05$; Table 1). Replicating the results of Experiments 1 and 2, gamblers tended to allow the die to roll for longer when attempting to 'hit' larger target values, $b=0.066,95 \% \mathrm{CI}[0.027,0.105], S E=0.020$. This equates to an increase in roll-time of $\approx 55 \mathrm{~ms}$ for every single value increase in target winning number. Die-roll times tended to be shorter in later stages of the game, $b=-0.011,95 \%$ CI $[-0.017,-0.005], S E=0.003$.

One-sample $t$-test showed that action-based IOC (as longer roll-times when trying to hit higher target winning numbers) were significant in both the stop-signal training group, $t(19)=3.34$, $p<.01$, Cohen's $d=.75$, and response-training control group, $t(19)=2.98, p<.01$, Cohen's $d=.67$. Participants in the stop-signal training group did not show any overall change in their actionbased IOC compared with those in the response-training group; i.e. the strength of association 
between die-roll times and target winning numbers did not differ markedly (Model 1 of Table 4), $b=-0.047,95 \% C I[-0.112,0.017], S E=0.032$.

As in Experiment 1, participants' action-based IOC were positively associated with stronger beliefs in the possibility of influencing the outcomes of the die-rolling game, $b=0.007,95 \% C I$ [0.001, 0.013], $S E=0.003$. Critically, the association between action-based IOC and dice-control beliefs was significantly diminished following stop-signal training, $b=-0.01595 \% C I[-0.025$, 0.004], $S E=0.005$ (Figure 3 and Model 2 of Table 4). Furthermore, the $\beta$-coefficient for this interaction remained statistically significant after removing thirteen participants with low dicecontrol beliefs (i.e., those who reported 'strongly disagree' to every item on the Dice-Control scale), $b=-0.021,95 \%$ CI [-0.041, -0.001$], S E=0.009$.

Table 4 and Figure 3 about here

\section{Discussion}

Experiment 3 demonstrates that an induction of motor caution following completion of a stopsignal task can diminish the expression of longer roll-times to 'hit' higher value winning numbers but, specifically, only in gamblers with relatively strong self-reported beliefs that they could influence the outcomes of the die-rolling game (as scores on the Dice-Control scale). These findings demonstrate that brief motor-caution training not only diminishes risk-taking behaviour in healthy (non-gambling) individuals (Stevens et al., 2015; Verbruggen et al., 2012) and other health-relevant behaviours (Allom, Mullan, \& Hagger, 2016; Jones et al., 2016) but can, in some 
gamblers at least, decouple instrumental attempts to manipulate a simulated die-roll to secure winning outcomes from their beliefs that these manipulations can be successful.

\section{General discussion}

Three experiments addressed the psychological mechanisms that mediate action-based illusions of control (IOC) in a simulated dice-rolling game for small monetary prizes. All three experiments replicate the finding that gamblers can express IOC in the actions afforded by dicebased games (Lim et al., 2014). These findings are unlikely to be attributable to uncontrolled variation in gambling problems within or between samples since (self-reported) clinical symptoms were low across all three experiments. Similarly, the findings cannot be attributed to the frequency of winning outcomes since the die-rolling outcomes were matched for comparisons within games and across participant groups. Rather, our findings suggest that action or motor-based biases within games of dice provide gamblers with the opportunity to express, in instrumental terms, their beliefs in their control over game outcomes (Wegner, 2004).

\section{Die-rolling, illusions of control and prize structures}

Experiment 1 demonstrated that action-based expressions of IOC in a die-rolling game is modulated by the correspondence between actions afforded by games and their prize structure (Kornblum et al., 1990). Specifically, our findings show that action-based IOC can be attenuated when one element of the game's structure is compatible with the available actions (higher winning numbers $\rightarrow$ longer die-rolls) while another element is incompatible (higher prize values $\rightarrow$ shorter die-rolls) compared to when both elements are compatible (higher winning numbers + larger prize values $\rightarrow$ longer die-rolls). Other aspects of numeric processing can be expressed in 
motor behaviour (Andres et al., 2004; Lindemann et al., 2007). Hand-grasping and -releasing speeds are quicker when responding to smaller and larger numbers, respectively (Andres et al., 2004) while people tend to execute small finger actions (as 'precision grips') faster when they see small numbers, and execute large grasping actions (as 'power grips') faster, and with more force, when they see large numbers (Lindemann et al., 2007). Our data suggest that the actions inherent in gambling games can activate shared mental representations of magnitude (Walsh, 2003), and that IOC in these games can be 'scaffolded' upon these underlying stimulus-response correspondences. Possibly, action-based IOC are modulated by the actions afforded by games with congruent prize structures (cf. Gibson, 1979), such as slots games that offer 'ladders' in which success at the higher steps offer larger prizes (Parke \& Griffiths, 2006).

Commented [A4]: Matthew, really nice - R

\section{Die-rolling, illusions of control and social features}

Experiment 2 showed that action-based IOC can reflect the joint betting patterns of a gambling co-actor. Experiment 2 shows that, in dice-rolling games, action-based IsOC can reflect the joint betting patterns of a gambling co-actor. Social facilitation of gambling can arise through several mechanisms. First, social facilitation can result in the transmission of erroneous beliefs in multiplayer gambling games (Delfabbro, 2004). Individuals can increase risk-taking patterns on slotmachines having learned about the gambling successes of other players (Kearney \& Drabman, 1992; Le Floch et al., 2005; Rockloff \& Dyer, 2007; Wohl \& Enzle, 2009); while observation of betting patterns can communicate mistaken and statistically inefficient beliefs about prize structures (Caron \& Ladouceur, 2003; Lefrancois, Chase, \& Joyce, 1988). Possibly, the behevauoural consequences of the transmission of erroneous beliefs between gambling coactores are consolidated by broader processes such as social conformity. 
Secondly, social facilitation of gambling can also increase skill-orientation (Langer, 1975) that can be enhanced by learning about other gamblers' 'successes and failures' (Caron \& Ladouceur, 2003; Dykstra \& Dollinger, 1990; Le Floch et al., 2005) or competition with others (Dewey, Seiffert, \& Carr, 2010). Observations of joint betting patterns can also offer social contexts that strengthen (mistaken) beliefs about personal skill (Langer, 1975). Thus, the congruent betting of gambling co-actors in the Bone Game of Experiment 2 may have been interpreted as endorsements of shooters' ability to hit target winning numbers (Wohl \& Enzle, 2009).

\section{Die-rolling, illusions of control and motor activation}

Experiment 3 demonstrated that an induced state of motor caution - through the completion of a standard stop-signal task - can decouple the link between action-based IOC and self-reported beliefs that it is possible to use the die to influence game outcomes. The induced state produced by the stop-signal task might involve the facilitation of an activated braking system to suppress motor responses to imperative signals once they have been initiated (Jahfari et al., 2010); or the proactive adjustment of response strategies that slow responses to minimise response errors (Verbruggen and Logan 2009). Whichever is the case, the results of Experiment 3 suggest that an induction of motor-caution has the capacity to interrupt instrumental attempts to exert control over gambling outcomes in gamblers who hold strong explicit beliefs on control.

\section{Clinical and harm-minimisation implications}

Current conceptions of how structural characteristics of gambling games can enhance the risk of gambling harms focus on the static features such as losses-disguised-as-wins, returns to player, 'near-misses', as well as sensory features such as console lights and sounds (Dixon et al, 2015; 
Loba, Stewart, Klein, \& Blackburn, 2001; Parke \& Griffiths, 2006; Reid, 1986). The findings from Experimental 1 and 2 highlight the potential for gambling-related harms to be amplified by the actions - and sense of active involvement - afforded by both structural and social features of games in vulnerable individuals. Our findings also raise the possibility of identifying complementary assays of IOCs as clinical outcomes of interventions that focus upon cognitive biases and errors such as cognitive behavioural therapy (Cowlishaw et al., 2012).

Still other data suggest that high rates of play on gambling machines may increase the risks of gambling-related harms (Linnet et al. 2010; Blaszczynski et al. 2001; Choliz 2010; Ladoucer and Sevigny 2006; Mentzoni et al. 2012; Worhunsky et al, 2017) and are associated with enhanced striatal dopamine release in pathological gamblers (Boileau et al. 2014). It is reasonable to assume that fast rates of play are associated with facilitatation of the motor actions required to play and control the game features, and raise the possibility that rapid rates of play increase the risk of harms by strengthening action-based IOC and their associated beliefs in control. Equally, it follows that putative harm-minimisation interventions or devices that reduce rates of play on machines may reduce the risks of harm by weakening action-based IOC. Possibly, such interventions might be most helpful for gamblers who show particular impairments in impulse or inhibitory control (Leeman \& Potenza, 2012). These, however, are possibilities for the future.

\section{Limitations and future research}

We acknowledge that our findings are subject to several limitations. First, our computersimulated die-rolling game has an artificiality compared to, for example, live casino craps or SicBo in Asia. Nevertheless, lab-based experiments afford opportunities to test underlying 
mechanisms and, we argue, provide insights into the structure and expression of IOC in commercial games. Second, another limitation reflects our choice of experimental participants. Further work will be needed to test these findings in female gamblers who sometimes show weaker gambling-related cognitive biases (Raylu \& Oei, 2004; Wardle et al., 2010).

Nevertheless, our results can probably generalise to the majority of male gamblers and point to future study of action-based IOC in individuals with significant gambling problems.

Finally, we acknowledge that we recruited relatively small samples of community gamblers. However, the repeated replication of our main findings across all studies, including Lim et al. (2014), and the consistent support of our main hypotheses suggest that the demonstration of action-based illusions of control are robust.

Notwithstanding these concerns, these findings extend previous investigations of IOC as declarative (if also false) propositional beliefs about gambling action-outcome contingencies. Our findings suggest that in gambling forms with an active involvement component, IOC can be partly 'embodied' in the motor, muscular and somatic systems that express them (Proffitt, 2006). 


\section{References}

Allom, V., Mullan, B., \& Hagger, M. (2016). Does inhibitory control training improve health behaviour? A meta-analysis. Health Psychology Review, 10(2), 168-186

Andres, M., Davare, M., Pesenti, M., Olivier, E., \& Seron, X. (2004). Number magnitude and grip aperture interaction. Neuroreport, 15(18), 2773-2777

Barry, D., \& Petry, N. M. (2008). Predictors of decision-making on the Iowa Gambling Task: Independent effects of lifetime history of substance use disorders and performance on the Trail Making Test. Brain and cognition, 66(3), 243-252

Billieux, J., Lagrange, G., Van der Linden, M., Lançon, C., Adida, M., \& Jeanningros, R. (2012). Investigation of impulsivity in a sample of treatment-seeking pathological gamblers: A multidimensional perspective. Psychiatry Research, 198(2), 291-296

Blaszczynski, A., \& Nower, L. (2002). A pathways model of problem and pathological gambling. Addiction, 97(5), 487-499

Brevers, D., Cleeremans, A., Verbruggen, F., Bechara, A., Kornreich, C., Verbanck, P., \& Noël, X. (2012). Impulsive action but not impulsive choice determines problem gambling severity. PloS one, 7(11), e50647

Campbell-Meiklejohn, D., Simonsen, A., Scheel-Krüger, J., Wohlert, V., Gjerløff, T., Frith, C. D., . . Møller, A. (2012). In for a penny, in for a pound: methylphenidate reduces the inhibitory effect of high stakes on persistent risky choice. Journal of neuroscience, 32(38), 13032-13038

Campbell-Meiklejohn, D., Wakeley, J., Herbert, V., Cook, J., Scollo, P., Ray, M. K., . . Rogers, R. D. (2011). Serotonin and dopamine play complementary roles in gambling to recover losses. Neuropsychopharmacology, 36(2), 402

Campbell-Meiklejohn, D., Woolrich, M. W., Passingham, R. E., \& Rogers, R. D. (2008). Knowing when to stop: The brain mechanisms of chasing losses. Biological Psychiatry, 63(3), 293-300. doi: DOI 10.1016/j.biopsych.2007.05.014

Caron, A., \& Ladouceur, R. (2003). Erroneous verbalizations and risk taking at video lotteries. British Journal of Psychology, 94, 189-194.

Casino Top 10. (2019). Online casino games guide - Our handbook to rules, strategy \& more. Retrieved from https://www.casinotop10.net/guide

Chambers, C. D., Garavan, H., \& Bellgrove, M. A. (2009). Insights into the neural basis of response inhibition from cognitive and clinical neuroscience. Neuroscience \& Biobehavioral Reviews, 33(5), 631-646

Chau, A. W., \& Phillips, J. G. (1995). Effects of perceived control upon wagering and attributions in computer Blackjack. Journal of General Psychology, 122(3), 253-269

Cole, T., Barrett, D. J. K., \& Griffiths, M. D. (2011). Social facilitation in online and offline gambling: A pilot study. International Journal of Mental Health and Addiction, 9(3), 240-247. doi: DOI 10.1007/s11469-010-9281-6

Cowlishaw, S., Merkouris, S., Dowling, N., Anderson, C., Jackson, A., \& Thomas, S. (2012). Psychological therapies for pathological and problem gambling. Cochrane Database of Systematic Reviews(11)

Davis, D., Sundahl, I., \& Lesbo, M. (2000). Illusory Personal Control as a Determinant of Bet Size and Type in Casino Craps Games. Journal of Applied Social Psychology, 30(6), $1224-1242$ 
Delfabbro, P. (2004). The stubborn logic of regular gamblers: Obstacles and dilemmas in cognitive gambling research. Journal of Gambling Studies, 20(1), 1-21

Delfabbro, P., \& Winefield, A. (1999). Poker-machine gambling: An analysis of within session characteristics. British Journal of Psychology, 90, 425-439. doi: Doi 10.1348/000712699161503

Delfabbro, P., \& Winefield, A. (2000). Predictors of irrational thinking in regular slot machine gamblers. Journal of Psychology, 134(2), 117-128

Dewey, J. A., Seiffert, A. E., \& Carr, T. H. (2010). Taking credit for success: the phenomenology of control in a goal-directed task. Consciousness and Cognition, 19(1), 48-62. doi: 10.1016/j.concog.2009.09.007

Dunn, D. S., \& Wilson, T. D. (1990). When the stakes are high - A limit to the illusion-of-control effect. Social Cognition, 8(3), 305-323

Dykstra, S. P., \& Dollinger, S. J. (1990). Model competence, depression, and the illusion of control. Bulletin of the Psychonomic Society, 28, 235-238

Fernandez-Duque, D., \& Wifall, T. (2007). Actor/observer asymmetry in risky decision making. Judgment and Decision Making Journal, 2(1), 1-8

First, M. B., Spitzer, R. L., Gibbon, M., \& Williams, J. B. W. (2002). Structured Clinical Interview for DSM-IV Axis-I Disorders, Research Version, Patient Edition. (SCID-I/P). New York: Biometrics Research.

Fortune, E. E., \& Goodie, A. S. (2012). Cognitive distortions as a component and treatment focus of pathological gambling: A review. Psychology of Addictive Behaviors, 26(2), 298

Friedland, N., Keinan, G., \& Regev, Y. (1992). Controlling the Uncontrollable - Effects of Stress on Illusory Perceptions of Controllability. Journal of Personality and Social Psychology, 63(6), 923-931

Gibson, J. J. (1979). The theory of affordances: The ecological approach to visual perception. Boston: Houghton Mifflin.

Goudriaan, A. E., Oosterlaan, J., De Beurs, E., \& Van Den Brink, W. (2006). Neurocognitive functions in pathological gambling: A comparison with alcohol dependence, Tourette syndrome and normal controls. Addiction, 101(4), 534-547

Grant, J. E., Steinberg, M. A., Kim, S. W., Rounsaville, B. J., \& Potenza, M. N. (2004).

Preliminary validity and reliability testing of a structured clinical interview for pathological gambling. Psychiatry Research, 128(1), 79-88. doi: DOI 10.1016/j.psychres.2004.05.006

Griffiths, M. D. (1994). The role of cognitive bias and skill in fruit machine gambling. British Journal of Psychology, 85, 351-369

Hardoon, K. K., \& Derevensky, J. L. (2001). Social influences involved in children's gambling behavior. . Journal of Gambling Studies, 17(3), 191-215

Henslin, J. M. (1967). Craps and magic. The American Journal of Sociology, 73(3), 316-330

Jahfari, S., Stinear, C. M., Claffey, M., Verbruggen, F., \& Aron, A. R. (2010). Responding with restraint: What are the neurocognitive mechanisms? Journal of Cognitive Neuroscience, 22(7), 1479-1492

Jones, A., Di Lemma, L. C., Robinson, E., Christiansen, P., Nolan, S., Tudur-Smith, C., \& Field, M. (2016). Inhibitory control training for appetitive behaviour change: A meta-analytic investigation of mechanisms of action and moderators of effectiveness. Appetite, 97, 1628 
Kornblum, S., Hasbroucq, T., \& Osman, A. (1990). Dimensional Overlap - Cognitive Basis for Stimulus-Response Compatibility - a Model and Taxonomy. Psychological Review, 97(2), 253-270

Ladouceur, R., Gaboury, A., Bujold, A., Lachance, N., \& Tremblay, S. (1991). Ecological validity of laboratory studies of videopoker gaming. Journal of Gambling Studies, 7(2), 109-116

Ladouceur, R., \& Sevigny, S. (2005). Structural characteristics of video lotteries: Effects of a stopping device on illusion of control and gambling persistence. Journal of Gambling Studies, 21(2), 117-131. doi: 10.1007/s10899-005-3028-5

Ladouceur, R., Sylvain, C., Boutin, C., Lachance, S., Doucet, C., \& Leblond, J. (2003). Group therapy for pathological gamblers: A cognitive approach. Behaviour research and therapy, 41(5), 587-596

Ladouceur, R., Sylvain, C., Boutin, C., Lachance, S., Doucet, C., Leblond, J., \& Jacques, C. (2001). Cognitive treatment of pathological gambling. Journal of Nervous and Mental Disease, 189(11), 774-780

Langer, E. J. (1975). The illusion of control. J Personality Soc Psychol, 32, 311-328

Langer, E. J. (1975). The illusion of control. Journal of Personality and Social Psychology, 32(2), 311-328

Le Floch, V., Martinez, F., \& Gaffie, B. (2005). L'annonce du resultat d'autrui: un second point de reference? Canadian Journal of Behavioural Science, 36(4), 310-320

Leeman, R. F., \& Potenza, M. N. (2012). Similarities and differences between pathological gambling and substance use disorders: A focus on impulsivity and compulsivity. Psychopharmacology, 219(2), 469-490. doi: 10.1007/s00213-011-2550-7

Lefrancois, J. R., Chase, P. N., \& Joyce, J. H. (1988). The Effects of a Variety of Instructions on Human Fixed-Interval Performance. Journal of the Experimental Analysis of Behavior, 49(3), 383-393. doi: DOI 10.1901/jeab.1988.49-383

Lim, M. S. M., Bowden-Jones, H., \& Rogers, R. (2014). Expressing gambling-related cognitive biases in motor behaviour: Rolling dice to win prizes. Journal of Gambling Studies, 30, 625-637

Lindemann, O., Abolafia, J. A., Girardi, G., \& Bekkering, H. (2007). Getting a grip on numbers: Numerical magnitude priming in object grasping. Journal of Experimental PsychologyHuman Perception and Performance, 33(6), 1400-1409. doi: Doi 10.1037/00961523.33.6.1400

Loba, P., Stewart, S. H., Klein, R. M., \& Blackburn, J. R. (2001). Manipulations of the features of standard video lottery terminal (VLT) games: Effects in pathological and nonpathological gamblers. Journal of Gambling Studies, 17(4), 297-320

Martinez, F., Bonnefon, J.-F., \& Hoskens, J. (2009). Active involvement, not illusory control, increases risk taking in a gambling game. Quarterly Journal of Experimental Psychology, 62(6), 1063-1071

Moore, S. M., \& Ohtsuka, K. (1999). Beliefs about control over gambling among young people, and their relation to problem gambling. Psychology of Addictive Behaviors, 13(4), 339347

Myrseth, H., Brunborg, G. S., \& Eidem, M. (2010). Differences in cognitive distortions between pathological and non-pathological gamblers with preferences for chance or skill games. Journal of Gambling Studies, 26(4), 561-569. doi: DOI 10.1007/s10899-010-9180-6 
Parke, J., \& Griffiths, M. (2006). The psychology of the fruit machine: The role of structural characteristics (revisited). International Journal of Mental Health Addiction, 4, 151-179

Proffitt, D. R. (2006). Embodied Perception and the Economy of Action. Perspectives on Psychological Science, 1(2), 110-122. doi: DOI 10.1111/j.1745-6916.2006.00008.x

Raven, J. (2000). The Raven's progressive matrices: change and stability over culture and time. Cognitive psychology, 41(1), 1-48. doi: 10.1006/cogp.1999.0735

Raylu, N., \& Oei, T. P. (2004). The gambling related cognitions scale (GRCS): Development, confirmatory factor validation and psychometric properties. Addiction, 99(6), 757-769. doi: DOI 10.1111/j.1360-0443.2004.00753.x

Reid, R. L. (1986). The psychology of the near miss. Journal of Gambhng Behavior, 2(1), 32-39

Rockloff, M. J., \& Dyer, V. (2007). An experiment on the social facilitation of gambling behavior. Journal of Gambling Studies, 23(1), 1-12. doi: DOI 10.1007/s10899-006-90424

Rockloff, M. J., Greer, N., \& Fay, C. (2011). The social contagion of gambling: How venue size contributes to player losses. Journal of Gambling Studies, 27(3), 487-497. doi: DOI 10.1007/s10899-010-9220-2

Rogers, R. D., Wielenberg, B., Wojtecki, L., Elben, S., Campbell-Meiklejohn, D., \& Schnitzler, A. (2011). Deep brain stimulation of the subthalamic nucleus transiently enhances losschasing behaviour in patients with Parkinson's Disease. Experimental Neurology, 231(1), 181-189

Rothbaum, F., Weisz, J. R., \& Snyder, S. S. (1982). Changing the World and Changing the Self a 2-Process Model of Perceived Control. Journal of personality and social psychology, 42(1), 5-37

Steenbergh, T. A., Meyers, A. W., May, R. K., \& Whelan, J. P. (2002). Development and validation of the Gamblers' Beliefs Questionnaire. Psychology of Addictive Behaviors, 16(2), 143-149. doi: Doi 10.1037//0893-164x.16.2.143

Stevens, T., Brevers, D., Chambers, C. D., Lavric, A., McLaren, I. P., Mertens, M., .. . Verbruggen, F. (2015). How does response inhibition influence decision making when gambling? Journal of Experimental Psychology: Applied, 21(1), 15

Strickland, L. H., Lewicki, R. J., \& Katz, A. M. (1966). Temporal Orientation and Perceived Control as Determinants of Risk-Taking. Journal of Experimental Social Psychology, 2(2), 143-151. doi: Doi 10.1016/0022-1031(66)90075-8

Toneatto, T., Blitz-Miller, T., Calderwood, K., Dragonetti, R., \& Tsanos, A. (1997). Cognitive distortions in heavy gambling. Journal of Gambling Studies, 13(3), 253-266

Verbruggen, F., Adams, R., \& Chambers, C. D. (2012). Proactive motor control reduces monetary risk taking in gambling. Psychological Science, 23(7), 805-815. doi: Doi $10.1177 / 0956797611434538$

Verbruggen, F., Adams, R. C., van't Wout, F., Stevens, T., McLaren, I. P., \& Chambers, C. D. (2013). Are the effects of response inhibition on gambling long-lasting? PloS one, 8(7), e70155

Walker, M. B. (1992). Irrational thinking among slot machine players. Journal of Gambling Studies, 8(3), 245-261

Walsh, V. (2003). A theory of magnitude: Common cortical metrics of time, space and quantity. Trends in Cognitive Sciences, 7(11), 483-488. doi: DOI 10.1016/j.tics.2003.09.002

Wardle, H., Moody, A., Spence, S., Orford, J., Volberg, R., Jotangia, D., . . Dobbie, F. (2010). British Gambling Prevalence Survey 2010. National Centre for Social Research. 
Wegner, D. M. (2004). Précis of the illusion of conscious will. Behavioral and Brain Sciences, 27(5), 649-659

Wohl, M. J. A., \& Enzle, M. E. (2009). Illusion of control by proxy: Placing one's fate in the hands of another. British Journal of Social Psychology, 48(1), 183-200. doi: Doi 10.1348/014466607x258696

Worhunsky, P. D., Potenza, M. N., \& Rogers, R. D. (2017). Alterations in functional brain networks associated with loss-chasing in gambling disorder and cocaine-use disorder. Drug \& Alcohol Dependence, 178, 363-371

Xian, H., Shah, K. R., Phillips, S. M., Scherrer, J. F., Volberg, R., \& Eisen, S. A. (2008).

Association of cognitive distortions with problem and pathological gambling in adult male twins. Psychiatry Research, 160(3), 300-307 


\section{Table 1.}

Descriptive statistics and group differences of gamblers in experiments 1,2 and 3.

\begin{tabular}{|c|c|c|c|c|c|c|c|c|}
\hline & \multicolumn{8}{|c|}{ Mean $(S D)$} \\
\hline & \multicolumn{4}{|c|}{$\begin{array}{l}\text { Experiment } 1 \\
\quad(n=60)\end{array}$} & \multirow[t]{2}{*}{$\begin{array}{l}\text { Experiment } 2 \\
\quad(n=32)\end{array}$} & \multicolumn{3}{|c|}{$\begin{array}{l}\text { Experiment } 3 \\
\quad(n=40)\end{array}$} \\
\hline & $\begin{array}{l}\text { Congruent } \\
\text { Group } \\
(n=20)\end{array}$ & $\begin{array}{l}\text { Incongruent } \\
\text { Group } \\
(n=20)\end{array}$ & $\begin{array}{l}\text { Neutral } \\
\text { Group } \\
(n=20)\end{array}$ & $p$-value & & $\begin{array}{l}\text { Stop-signal } \\
\text { Training } \\
\text { Group } \\
(n=20)\end{array}$ & $\begin{array}{l}\text { Response } \\
\text { Training } \\
\text { Group } \\
(n=20)\end{array}$ & $p$-value \\
\hline Age & $28.9(11.2)$ & 28.3(11.2) & $28.9(9.1)$ & $>.05^{\mathrm{a}}$ & $28.8(10.1)$ & $29.5(10.4)$ & $28.9(9.6)$ & $>.05^{\mathrm{d}}$ \\
\hline Non-verbal cognitive ability & $45.6(12.8)$ & 46.1(11.0) & $49.5(8.2)$ & $>.05^{\mathrm{a}}$ & $50.1(7.0)$ & $50.7(6.9)$ & $49.6(8.4)$ & $>.05^{\mathrm{d}}$ \\
\hline Gambling problems & $0.7(1.4)$ & $0.7(1.7)$ & $0.6(2.0)$ & $>.05^{\mathrm{b}}$ & $1.0(1.5)$ & $0.4(1.1)$ & $0.3(0.7)$ & $>.05^{\mathrm{b}}$ \\
\hline Gambling frequency, $N(\%)$ & & & & $>.05^{\mathrm{c}}$ & & & & $>.05^{\mathrm{c}}$ \\
\hline Once a week or more & $11(55.0)$ & $16(80.0)$ & $11(55.0)$ & & $16(50.0)$ & $11(55.0)$ & $10(50.0)$ & \\
\hline Less than once a week & $9(45.0)$ & $4(20.0)$ & $9(45.0)$ & & $16(50.0)$ & $9(45.0)$ & $10(50.0)$ & \\
\hline Gambling-related Cognitions & & & & & & & & \\
\hline Illusions of control/ GRCS-IOC & $6.1(2.9)$ & $8.4(4.4)$ & $5.9(3.5)$ & $>.05^{\mathrm{a}}$ & $7.2(4.9)$ & $6.2(4.3)$ & 7.0(4.9) & $>.05^{\mathrm{d}}$ \\
\hline Total score/ GRCS & $55.7(15.6)$ & $62.2(20.9)$ & $56.1(17.9)$ & $>.05^{\mathrm{a}}$ & $56.2(22.5)$ & $55.6(21.5)$ & $53.5(21.5)$ & $>.05^{\mathrm{d}}$ \\
\hline
\end{tabular}

Note: Non-verbal cognitive ability as measured by the Raven's Progressive Matrices (Raven, 2000); Gambling problems as measured by the Structured Clinical Interview for Pathological Gambling (SCI-PG; Grant et al., 2004); Gambling-related Cognitions as measured by the Gambling-related Cognitions Scale (Raylu \& Oei, 2004); ${ }^{\text {a }}$ One-way Analysis of Variance (ANOVA); ${ }^{\text {b }}$ non-parametric Kruskal-Wallis test (distribution within groups was non-normal); ${ }^{\mathrm{c}} \chi^{2}$ test (fewer than $20 \%$ of the contingency table cells had frequencies $<5$ ); ${ }^{\mathrm{d}}$ Independent sample $t$ test. 
Table 2.

Experiment 1. Two regressions of participant $\beta$-coefficient values (for target winning numbers) against experimental groups (correspondences of game features and prize values), dice-control beliefs, trait illusions of control, age and non-verbal cognitive ability in 60 gamblers

\begin{tabular}{llclllll}
\hline & \multicolumn{3}{c}{ Model 1 } & \multicolumn{3}{c}{ Model 2} \\
\hline & $b$ & SE $b$ & $\beta$ & $b$ & SE $b$ & $\beta$ \\
\cline { 2 - 7 } Constant & -.011 & .043 & & -.013 & .044 \\
Age & .000 & .001 & .058 & .000 & .001 & .049 \\
Non-verbal cognitive ability/Ravens & .000 & .001 & .034 & .000 & .001 & .030 \\
Trait illusions of control/GRCS-IOC & -.003 & .002 & -.214 & -.003 & .002 & -.232 \\
Perceived dice control/Dice-control Beliefs Scale & .004 & .001 & $.443^{* *}$ & .005 & .002 & $.508^{*}$ \\
Congruent (vs. Neutral) & .010 & .014 & .097 & .012 & .027 & .117 \\
Incongruent (vs. Neutral) & -.035 & .014 & $-.358^{*}$ & -.020 & .030 & -.202 \\
Perceived dice control"Congruent (vs. Neutral) & - & - & - & .000 & .003 & -.017 \\
Perceived dice control"Incongruent (vs. Neutral) & - & - & - & -.002 & .003 & -.188 \\
\hline
\end{tabular}

Note: $R^{2}=.30$ (Models 1 and 2 ); ${ }^{*} p<.05 ;{ }^{* *} p<.01$; Ravens - Raven's Progressive Matrices (Raven, 2000); GRCS-IOC - scores on the IOC subscale of the Gambling Related Cognitions Scale (Raylu \& Oei, 2004); Dice-control Beliefs Scale - scores on the adapted state measure of mistaken beliefs that the animated die can be controlled (Ladouceur \& Sevigny, 2005); Congruent, Incongruent, Neutral experimental conditions of the die-rolling game. 


\section{Table 3.}

Experiment 2. Regression of participant $\beta$-values (for the interaction effect of die target values and joint betting) against dice-control beliefs and trait illusions of control, controlling for age and non-verbal cognitive ability in 32 gamblers completing a dyadic dice-rolling game ('Bone

Game'); see text.

\begin{tabular}{llll}
\hline & $b$ & SE $b$ & $\beta$ \\
\hline Constant & .105 & .226 & \\
Age & $<.001$ & .003 & -.020 \\
Non-verbal cognitive ability/Ravens & .002 & .004 & .088 \\
Trait illusions of control/GRCS-IOC & .006 & .006 & .205 \\
Perceived dice control/Dice-control Beliefs Scale & $<.001$ & .005 & -.012 \\
\hline
\end{tabular}

Note: $R^{2}=.04$; Ravens - Raven's Progressive Matrices (Raven, 2000); GRCS-IOC - scores on the IOC subscale of the Gambling Related Cognitions Scale (Raylu \& Oei, 2004). 


\section{Table 4.}

Experiment 3. Two regressions of participant $\beta$-values (for die target winning numbers) against experimental training group and dice-control scores, controlling for trait illusions of control, age and non-verbal cognitive ability in 40 gamblers that received or did not receive an induction of motor caution before completing a simulated dice-rolling game for small monetary prizes.

\begin{tabular}{llcccccc}
\hline & \multicolumn{3}{c}{ Model 1 } & \multicolumn{3}{c}{ Model 2} \\
\cline { 2 - 8 } & $B$ & SE $B$ & $\beta$ & $B$ & SE B & $\beta$ \\
\hline Constant & & & .089 & .130 & & -.084 & .134 \\
Age & $<-.001$ & .002 & -.002 & .001 & .002 & .103 \\
Non-verbal cognitive ability/Ravens & -.001 & .002 & -.064 & .000 & .002 & .008 \\
Trait illusions of control/GRCS-IOC & -.004 & .004 & -.168 & -.004 & .004 & -.159 \\
Perceived dice control/Dice-control Scale & .007 & .003 & $.393^{*}$ & .016 & .004 & $.929^{* * * *}$ \\
Group/stop-signal vs double-response training & -.047 & .032 & -.234 & .102 & .060 & .502 \\
Perceived dice control*Experimental condition & - & - & - & -.015 & .005 & $-1.025^{* * *}$ \\
\hline
\end{tabular}

Note: $R^{2}=.35$ (Model 2); * $p<.05 ; * * * p<.001$; Ravens - Raven's Progressive Matrices (Raven, 2000); GRCS-IOC - scores on the IOC subscale of the Gambling Related Cognitions Scale (Raylu \& Oei, 2004); Dice-control Scale - Adapted state measure of mistaken beliefs that the animated die can be controlled (Ladouceur \& Sevigny, 2005); Group/stop signal training vs. response training on a motor caution task; Model 2 includes the interaction term for group * Dice control score. 


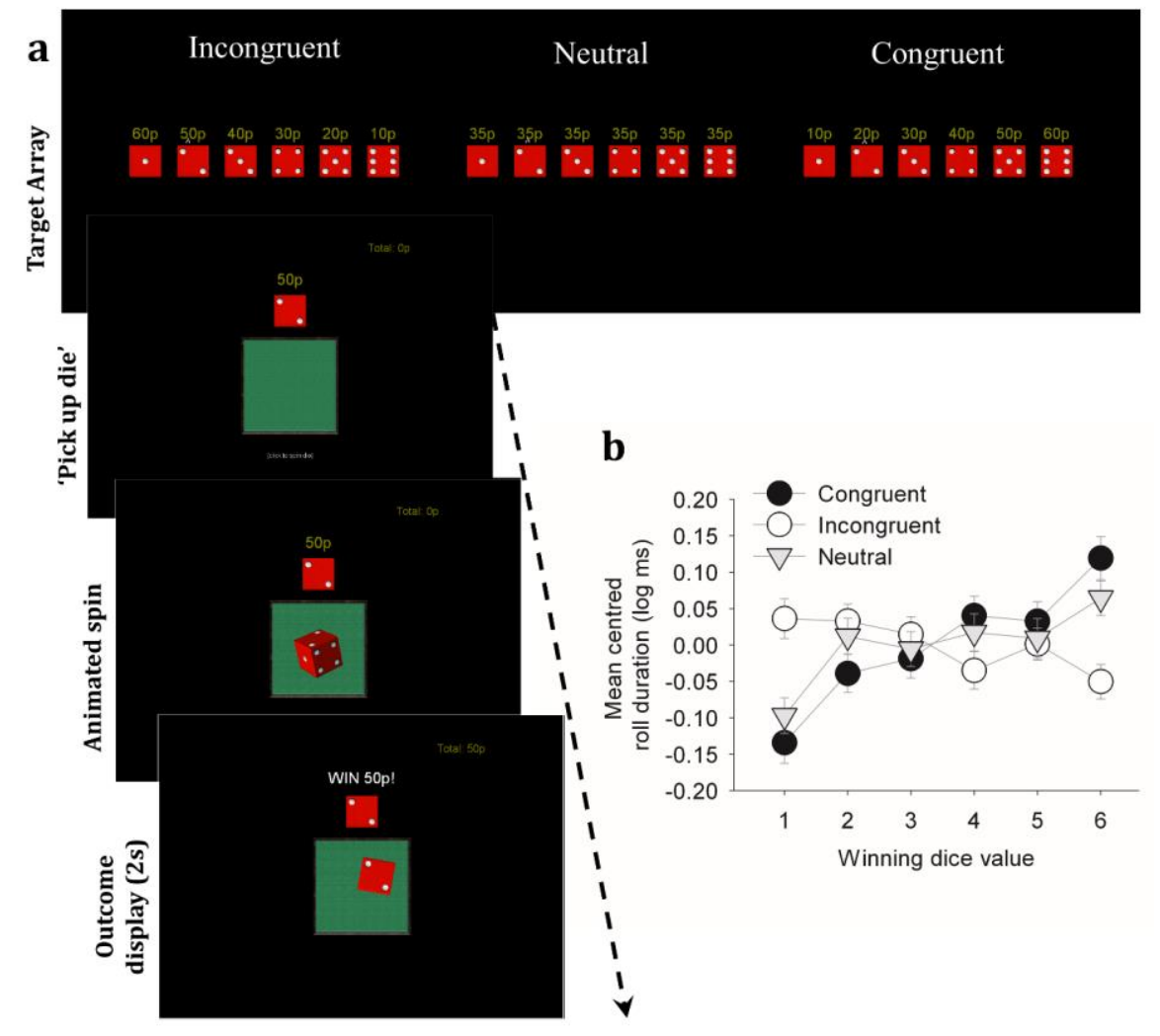

Figure 1 


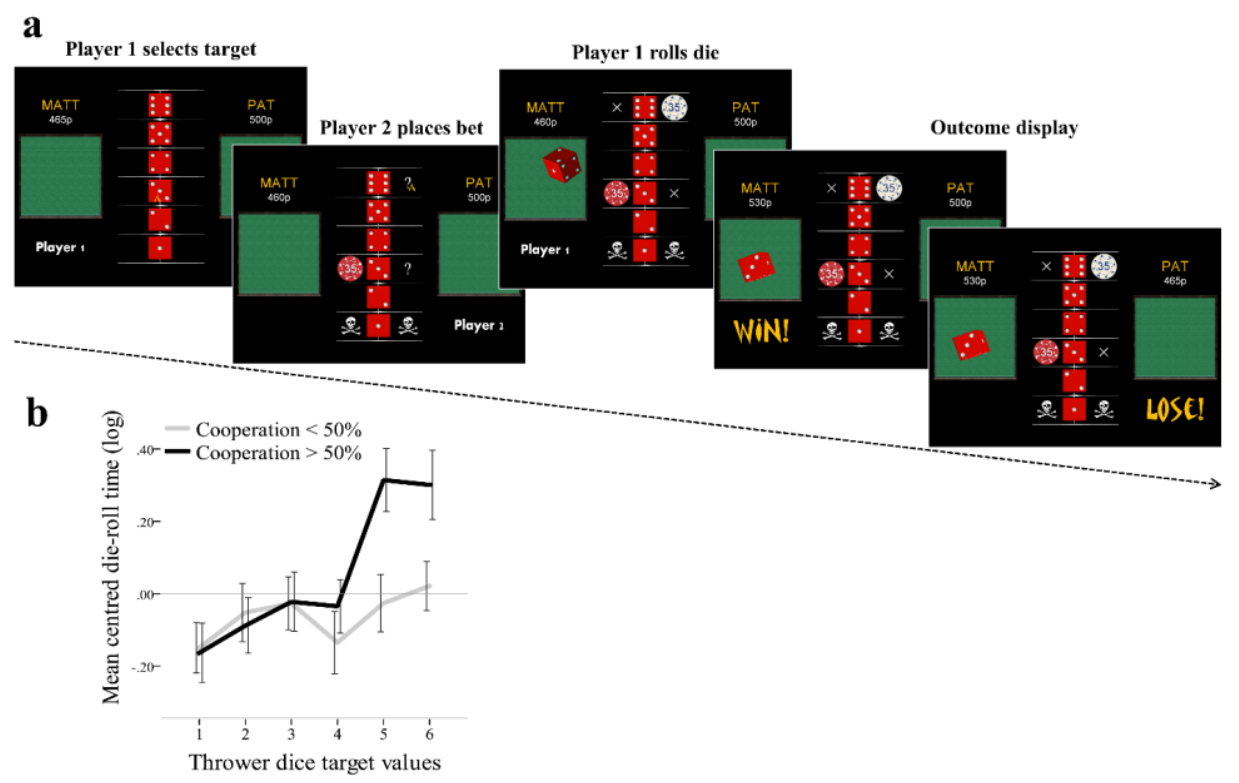

Figure 2 


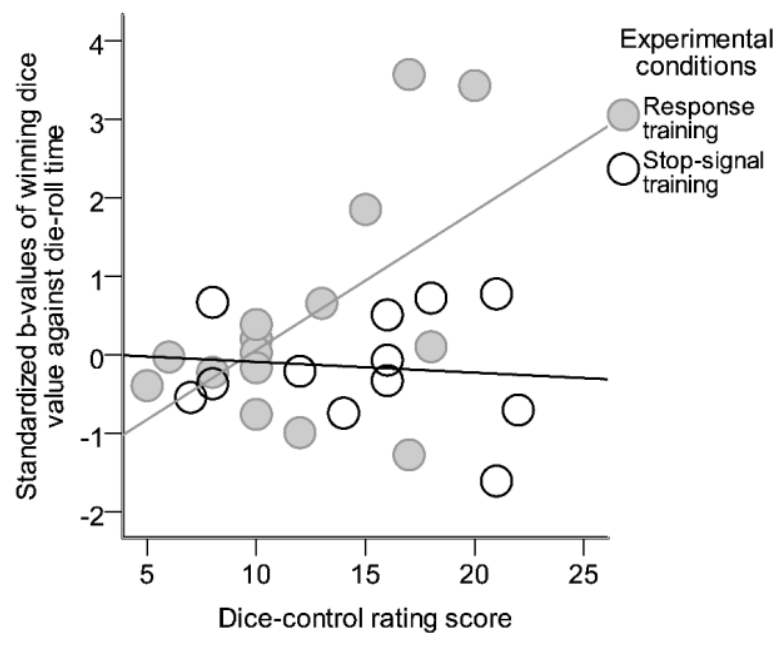

Figure 3 


\section{Figure captions}

Figure 1 (a) The top panels illustrate the 3 different experimental conditions of the Die-rolling game; the incongruent, neutral and congruent groups. The arrow indicates a play sequence of the incongruent experimental condition in the Die-rolling Game. The computer reads out ' 2 ' as the target and gamblers acknowledge the target by clicking on the prize above the announced target (i.e., 50p in this case). Once this is done, the option to click and spin an animated die is given. Participants click to spin the die and upon release the animation slows and presents the outcome. In this play sequence, the participant obtains the target 2 and wins the 50p prize; and (b) plot of gambler-centred roll-time (log ms) as a function of the size of die targets.

Figure 2 (a) An example of a display sequence for one play of the 'Bone Game'; in this instance, the computer reads out ' 3 ' as the 'shooter's ('Matt's') target. Matt would win $70 \mathrm{p}$ if he rolled the number 3, but lose 35p if he rolled the number 6; conversely, the betting partner ('Pat') would win 70p if the participant 1 rolled the number 6 , but lose $35 p$ if he rolled the number 3 . All bets are returned if the numbers 2,4 , and 5 are rolled, and all bets are forfeited if the skull and crossbones target of 1 is rolled. In this go, the number 3 is obtained, so the shooter wins and the betting partner loses; (b) Mean (and SEs) of thirty two gambler-centred die-roll times in milliseconds (natural logarithmic transformed) as a function of target winning number and joint or shared betting patterns of the 'shooter' and the 'betting partner'.

Figure 3 Plot of forty regular (but not problematic) gamblers' tendency to roll dice for longer when attempting large targets, as a function of Dice-control Scale scores; lines represent the experimental conditions of stop-signal training (black line) versus response training (grey line). 


\section{Footnote}

${ }^{\mathrm{i}}$ (Bank) craps is the most popular casino-based table game that has a vital aspect of active involvement through the rolling of (pairs of) dice to win bets on combinations of dice outcomes for monetary prizes. 